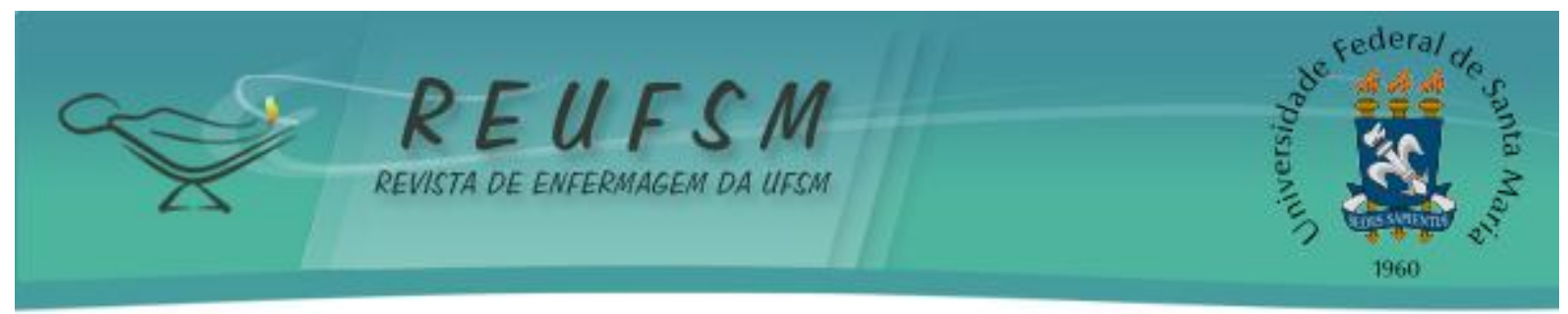

ARTIGO ORIGINAL

\title{
MÉTODO CANGURU: PERCEPÇÕES DA EQUIPE DE ENFERMAGEM EM TERAPIA INTENSIVA NEONATAL
}
KANGAROO METHOD: PERCEPTIONS OF THE NURSING TEAM IN NEONATAL INTENSIVE THERAPY

MÉTODO MADRE CANGURO: PERCEPCIONES DEL EQUIPO DE ENFERMERÍA EN TERAPIA INTENSIVA NEONATAL

\author{
Gabriela Vieira Mantelli ${ }^{1}$ \\ Márcia Rejane Strapasson ${ }^{2}$ \\ Aline Aparecida Pierotto ${ }^{3}$ \\ Jenifer Miguel Renosto ${ }^{4}$ \\ Juliana Fernandes da Silva ${ }^{5}$
}

Doi: $10.5902 / 2179769221182$

RESUMO: Objetivo: conhecer a percepção da equipe de enfermagem de um hospital privado quanto à prática do Método Canguru, implementada durante a internação de recém-nascidos na Unidade de Tratamento Intensivo Neonatal. Método: estudo qualitativo, exploratório e descritivo, realizado na Unidade de Tratamento Intensivo Neonatal em um hospital privado de Porto Alegre/RS. Participaram 15 profissionais da equipe de enfermagem, por meio de entrevista semiestruturada. Resultados: emergiram quatro categorias: a percepção da equipe de enfermagem quanto à prática do Método Canguru; as dificuldades encontradas no processo de implementação dessa prática; os benefícios encontrados no processo de implementação desse método; e as contribuições da equipe de enfermagem neonatal na implementação do método. Conclusão: a proposta do Método Canguru requer mudanças de paradigmas relativos ao cuidado humanizado do recémnascido prematuro e de baixo peso.

Descritores: Método Canguru; Enfermagem neonatal; Prematuro; Humanização da assistência; Enfermagem.

ABSTRACT: Aim: this study aims at investigating the perceptions of a private hospital nursing staff on the Kangaroo Care practices applied to newborns hospitalized in the Neonatal Intensive Care Unit. Method: qualitative, exploratory and descriptive study, conducted at the Neonatal Intensive Care Unit a private hospital in Porto Alegre/RS. Fifteen professionals from the nursing team participated in the study and semi-structured interview was used. Results: four thematic categories emerged: the perception of the

\footnotetext{
${ }^{1}$ Enfermeira. Universidade do Vale do Rio dos Sinos - UNISINOS, São Leopoldo, Rio Grande do Sul. Brasil. gabrielamantelli@hotmail.com

${ }^{2}$ Enfermeira. Mestre em Enfermagem pela Escola de Enfermagem da Universidade Federal do Rio Grande do Sul - UFRGS. Docente do Curso de Graduação em Enfermagem da Universidade do Vale do Rio dos SinosUNISINOS, São Leopoldo, Rio Grande do Sul. Brasil.marciastra@unisinos.br

${ }^{3}$ Enfermeira. Mestre em Saúde da Criança pela Pontíficia Universidade Católica do Rio Grande do SulPUCRS. Docente do Curso de Graduação em Enfermagem da Universidade do Vale do Rio dos SinosUNISINOS, São Leopoldo, Rio Grande do Sul. Brasil. apierotto@unisinos.br

${ }^{4}$ Enfermeira. Universidade do Vale do Rio dos Sinos - UNISINOS, São Leopoldo, Rio Grande do Sul. Brasil. jenirenosto@yahoo.com.br

${ }^{5}$ Enfermeira. Universidade do Vale do Rio dos Sinos - UNISINOS, São Leopoldo, Rio Grande do Sul Brasil. ju_f_fernandes@hotmail.com
} 


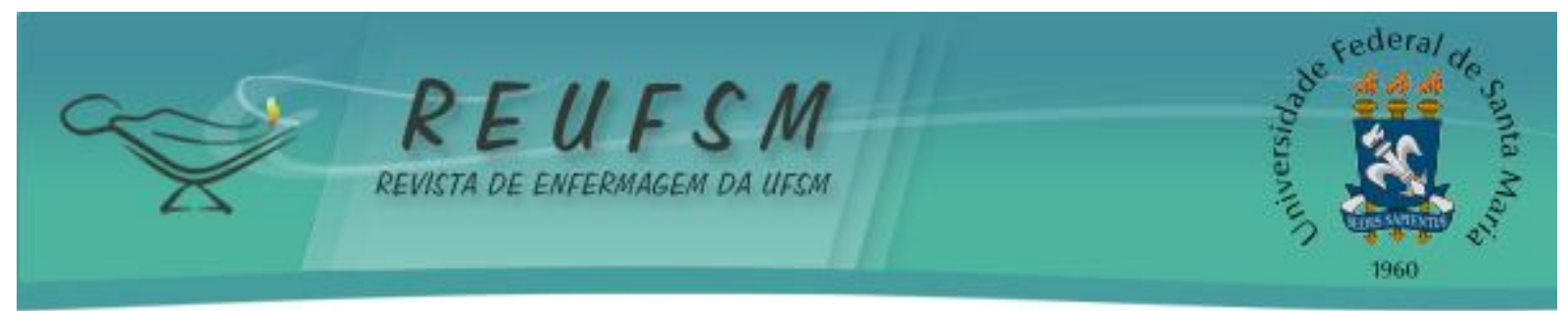

nursing team and the practice of Kangaroo Care; the difficulties found in the implementation of these practice; the benefits found after implementing the method; the contributions of neonatal nursing staff for the implementation of the method. Conclusion: the propose to implement Kangaroo Care method requires a change of paradigms on the humanized care of the premature and the underweight newborn.

Descriptors: Kangaroo-mother care method; Neonatal nursing; Infant premature; Humanization of assistance; Nursing.

RESUMEN: Objetivos: investigar la percepción del equipo de enfermería de un hospital privado sobre la práctica del Método Madre Canguro implementado durante la hospitalización de recién nacidos en una Unidad de Cuidados Intensivos Neonatales (UCIN). Método: estudio cualitativo, exploratorio y descriptivo, realizado en la UCIN de un hospital privado de Porto Alegre/RS. Participaron 15 profesionales del equipo de enfermería, por medio de entrevista semiestructurada. Resultados: se identificó cuatro categorías temáticas: la percepción del equipo de enfermería sobre la práctica del Método Madre Canguro; las dificultades encontradas en el proceso de implementación de esta práctica; los beneficios encontrados en el proceso de implementación de este método; y las contribuciones del equipo de enfermería neonatal en la aplicación del método. Conclusión: la propuesta del Método Madre Canguro necesita cambios de paradigma en relación al cuidado humanizado de los recién nacidos prematuros y de bajo peso.

Descriptores: Método madre-canguro; Enfermería neonatal; Prematuro; Humanización de la atención; Enfermería.

\section{INTRODUÇÃO}

Em 2011, no Brasil, a taxa de prevalência de crianças prematuras foi de $11,8 \%$. As regiões Sudeste e Sul apresentaram as maiores taxas, com 12,5\% e 12\%, respectivamente, seguidas pelas regiões Centro-Oeste, com 11,5\%, Nordeste, com 10,9\%, e Norte, com 10,8\%. Esse cenário tem balizado a demanda crescente de Unidades de Terapia Intensiva Neonatal (UTIN). ${ }^{1}$

Em relação a isso, em 1979, no Instituto Materno-Infantil da cidade de Bogotá (Colômbia), os médicos Edgar Rey Sanabria e Hector Martinez Gómez, amparados em dados epidemiológicos de mortalidade neonatal, constataram a necessidade de implementar e normatizar o cuidado ao recém-nascido prematuro e de baixo peso por meio do Método Canguru (MC). 0 método consiste no posicionamento supino do neonato prematuro entre os seios maternos, e o contato pele a pele entre a mãe e o recém-nascido. ${ }^{2}$ Esse método foi adotado no Brasil, sendo o primeiro país a reconhecê-lo como política pública de saúde, no Sistema Único de Saúde (SUS), padronizando e sistematizando a sua utilização no atendimento por meio da Portaria $72 / 2000 .^{3}$

0 método deve ser realizado precocemente entre o bebê e a mãe ou familiares, e a equipe de saúde deve estar habilitada para a promoção desse cuidado. Assim, o paradigma do cuidado humanizado com o recém-nascido prematuro ou de baixo peso e sua família requer respeito quanto às suas características e individualidade. ${ }^{3}$ Para tal, os pais dessa criança também necessitam de atenção, apoio e consideração frente às suas especificidades ${ }^{4}$, e os profissionais da saúde, especialmente a equipe de enfermagem, têm importante papel a ser desenvolvido no cuidado com o recém-nascido de baixo peso e na implementação do MC na UTIN. ${ }^{5}$

Constata-se que, no cotidiano do cuidado, o método oferece benefícios ao recémnascido de baixo peso quando implementado precocemente e/ou durante a internação neonatal. Nessa perspectiva, o recém-nascido internado na UTIN depara-se com um 


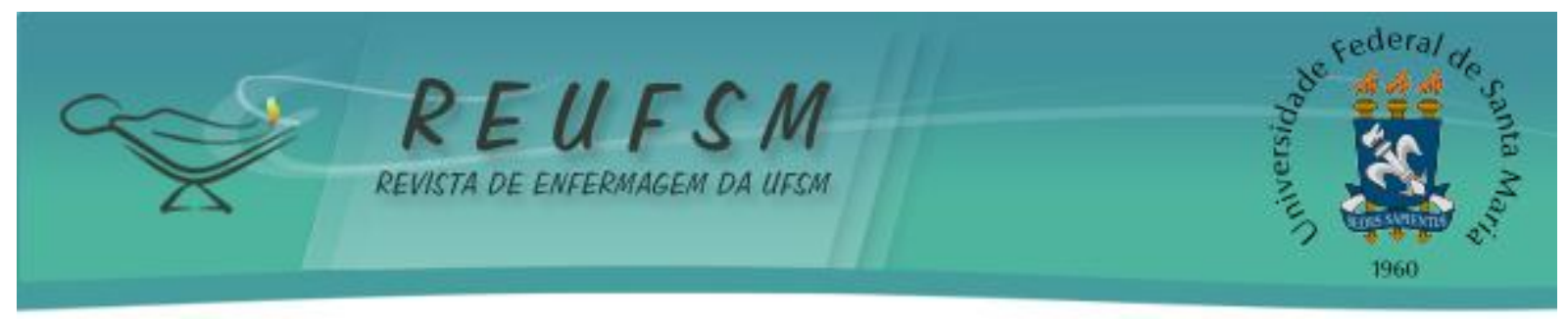

ambiente de alta complexidade, com enfoque tecnológico e intervencionista, que, na maioria das vezes, requer a separação precoce de sua mãe, o uso excessivo de tecnologias duras e de procedimentos invasivos.

Frente a esse cenário, o $M C$ compreende cuidados técnicos com o recém-nascido prematuro ou de baixo peso que vão além da posição canguru, como, por exemplo, manuseio, cuidados com luz, som, dor, acolhimento à família, promoção do vínculo mãe/bebê e do aleitamento materno, entre outros. ${ }^{6}$

Este estudo encontra relevância na importância atribuída à proposta do $M C$, uma vez que esse método se configura como uma prática baseada em evidências e tem grande impacto na redução da mortalidade neonatal ${ }^{3}$. A abordagem dessa prática vai ao encontro das políticas de humanização do recém-nascido de baixo peso, e das propostas do Ministério da Saúde, que visam uma assistência baseada em evidências e na integralidade do cuidado. ${ }^{3}$

Este estudo justifica-se pela escassez de hospitais privados no Rio Grande do Sul que adotam o método. Acredita-se que o cuidado neonatal requer, em primeiro lugar, mudanças de paradigma no cuidado multidisciplinar na UTIN. Contudo, a equipe de enfermagem pode ser protagonista das mudanças, uma vez que se encontra na linha de frente desse cuidado. Para isso, é preciso conhecer os benefícios que o método oferece para o neonato e sua família e buscar o aperfeiçoamento constante, a fim de desenvolver competências e habilidades específicas na implementação das etapas do MC.

Conhecer a percepção da equipe de enfermagem quanto à prática do MC implementada na UTIN possibilitará identificar as nuances do cuidado humanizado para com o recém-nascido de baixo peso, as possíveis dificuldades encontradas no processo de implementação do método, assim como facilidades e iniciativas tomadas pela enfermagem como contribuições para a qualificação do cuidado. Assim, o MC destaca-se no cuidado ao neonato de baixo peso como uma prática que utiliza uma tecnologia leve, capaz de aproximar a família dos cuidados com o recém-nascido. ${ }^{5}$

Espera-se, com este estudo, contribuir para a implementação de mudanças nas práticas de atenção neonatal e para o fortalecimento das políticas de humanização do nascimento, para que possibilite discussões, reflexões e subsídios para qualificar o atendimento humanizado ao recém-nascido de baixo peso e prematuro.

Portanto, questiona-se: qual a percepção da equipe de enfermagem de um hospital privado quanto à prática do $M C$ implementada durante a internação do recém-nascido na UTIN? Este estudo tem como objetivo de conhecer a percepção da equipe de enfermagem de um hospital privado acerca da prática do MC na UTIN.

\section{MÉTODO}

Trata-se de uma pesquisa exploratória, descritiva, com enfoque qualitativo. ${ }^{7} \mathrm{~A}$ coleta de dados foi realizada na UTI Neonatal de um hospital privado, que apoia o ensino e a pesquisa, localizado em Porto Alegre/RS, no período de janeiro de 2015 a março de 2015. Participaram do estudo enfermeiros e técnicos de enfermagem que trabalham na UTIN do hospital em estudo.

Como critério de inclusão, foi estabelecida a participação de enfermeiros e técnicos de enfermagem que atuam na UTIN, mesmo que na qualidade de folguista, e que trabalham há mais de um ano na unidade. Como critério de exclusão, determinou-se a não participação daqueles que estavam em licença no período da coleta dos dados.

Para a definição do número de entrevistas, seguiu-se o conceito de Gaskel, ${ }^{8}$ que menciona que estudos que utilizam a entrevista como ferramenta para coleta de dados devem ter entre 15 participantes e 25 participantes. Por isso, foram entrevistados 15 


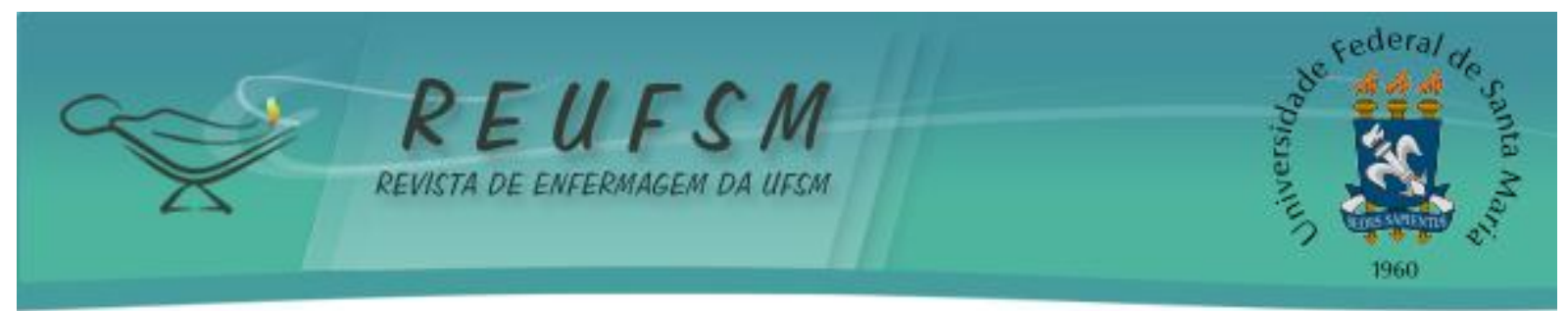

profissionais entre enfermeiros(as) e técnicos(as) de enfermagem que atuam na UTIN, sendo nove técnicos de enfermagem e seis enfermeiros.

Os dados foram coletados por meio de uma entrevista semiestruturada, contendo um roteiro com quatro questões: a) qual a percepção do $M C$ para a equipe de enfermagem de um hospital privado no cuidado ao recém-nascido internado na UTIN?; b) quais as dificuldades encontradas pela equipe de enfermagem dessa instituição na implementação dessa prática?; c) que ações de enfermagem incentivam a prática do MC durante a internação do recém-nascido na UTIN?; d) quais são os benefícios do método para o RN e sua mãe/família durante o período de internação na UTIN?

As entrevistas foram realizadas com tempo médio de 30 minutos, no ambiente hospitalar, em sala reservada, e com agendamento prévio com os entrevistados, tendo sido gravadas e, posteriormente, transcritas e analisadas. Os nomes dos entrevistados foram alterados para preservar seu anonimato, optando-se pela letra "E", de "entrevistado", seguida por uma sequência numérica aleatória, sem caracterizar a sequência das entrevistas.

Determinaram-se quatro categorias, espelhadas nas questões da entrevista semiestruturada, e, a partir dos instrumentos de pesquisa, puderam-se coletar informações para dar suporte à análise.

Para a execução deste estudo, foram observadas as questões éticas, conforme Resolução Ministerial $n .^{\circ} 466 / 2012$, que trata da pesquisa com seres humanos. ${ }^{9} 0$ projeto de pesquisa foi aprovado pelo Comitê de Ética e Pesquisa (CEP) da Universidade do Vale do Rio dos Sinos - UNISINOS, e pelo CEP da instituição coparticipante, sob o protocolo $\mathrm{n} .^{\circ}$ $911.741 / 2014$.

\section{RESULTADOS}

Com base nas entrevistas, e considerando-se as quatro categorias estabelecidas, o estudo mostrou os seguintes cenários:

\section{A percepção do Método Canguru para a equipe de enfermagem neonatal}

O MC é identificado pela equipe de enfermagem, quando mencionado por uma das entrevistadas, como uma prática para garantir a humanização no cuidado do recémnascido, conforme se observa na fala que segue:

é um método que visa à humanização do cuidado. É muito importante o contato pele a pele entre mãe e bebê para fortalecer o vínculo, deixar o bebê mais tranquilo.(E1)

No entanto, percebe-se uma preocupação significativa com o recém-nascido prétermo quando mencionado que a prática do $M C$ remete à formação de vínculo entre mãe e filho e, enfatizado a importância da implementação dessas ações, o mais rapidamente possível, com o prematuro. Para a entrevistada o contato pele a pele torna-se importante para formação de vínculo entre o binômio mãe/bebê, como relatado a seguir:

eu acho que melhora a questão do vínculo da mãe e do bebê, principalmente com o bebê prematuro, que acaba nascendo antes do tempo, sendo importante esse vínculo, esse contato precoce. (E7) 


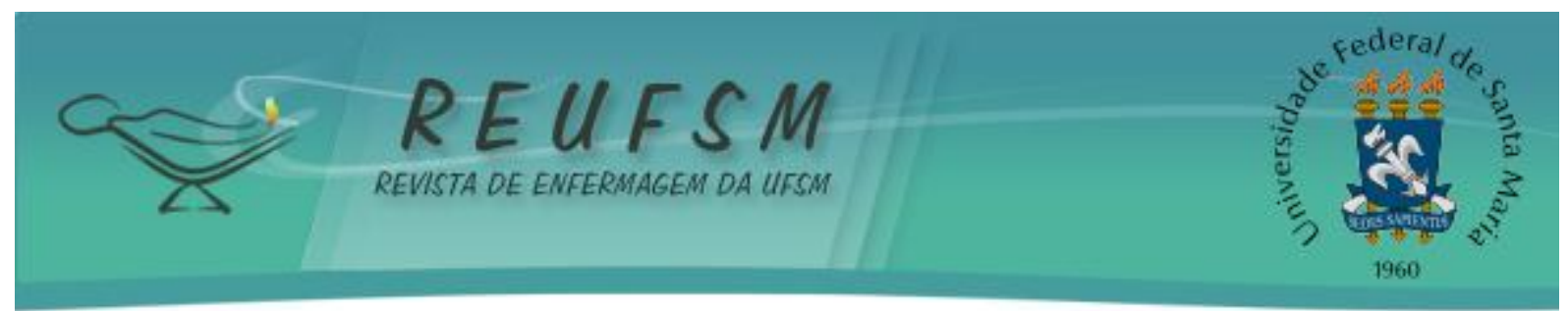

A família é vista como núcleo indispensavél no processo de internação e tratamento do neonato na UTIN, a partir dos pressupostos da atenção ao cuidado humanizado. Para uma das entrevistadas a prática integra a possibilidade de outras pessoas da família, especialmente o pai, participarem do cuidado e da construção do vínculo com o recémnascido:

o vínculo não é apenas da mãe com o bebê, mas também do pai, pois ele também pode fazer o contato pele a pele. (E10)

No entendimento da entrevistada o MC pode contribuir no desenvolvimento e na melhoria dos desfechos de saúde, especialmente para o recém-nascido prematuro que permanece por mais tempo internado. Este processo, também pode beneficiar a mãe quanto as questões constitutivas da maternidade como mostra a fala a seguir:

acho que é muito importante ter contato pele a pele com a mãe, porque muitas vezes o bebê fica ali na incubadora. É importante para o desenvolvimento tanto dele quanto da mãe.(E4)

Dificuldades na implementação do Método Canguru na unidade de tratamento intensivo neonatal

A falta de capacitação para a implemetação do $M C$ foi mencionada por uma das entrevistadas:

a dificuldade é que não é feito um treinamento sobre o método, pois nem todo mundo tem o conhecimento. (E1)

A resistência dos profissionais quanto à mudança de paradigma na assistência do cuidado humanizado ao recém-nascido constitui-se um dificultador na implementação do método:

por não ter o trabalho de humanização com todos, tem muita gente que ainda é muito fechada para pôr o bebê no colo. (E4)

No entanto, para que o cuidado ao neonato internado na UTIN seja implementado de forma integral e individualizado, torna-se indipensavél a criação de Protocolo Operacional Padrão (POP) e normativas institucionais. A falta de um POP para a implementação do $M C$ foi citado como uma dificuldade que inclusive reflete na autonomia da equipe de enfermagem na operacionalização do cuidado.

É uma questão de processo de implementação do Método Canguru como um todo. (E2)

Neste contexto, as condições clínicas e a prematuridade do neonato podem tornarse impedimentos para a implementação do $M C$. A falta de consenso pela comunidade científica quanto a idade e peso adequado do recém-nascido para a indicação do $M C$ podem dificultar esta prática. No entanto, normativas e protocolos institucionais podem contribuir para minimizar estas dificuldades. A fala a seguir reforça estas considerações:

eu acho que a dificuldade é mais em termo do estado do bebê, da sua prematuridade, pois, às vezes, tem bebês intubados, com 


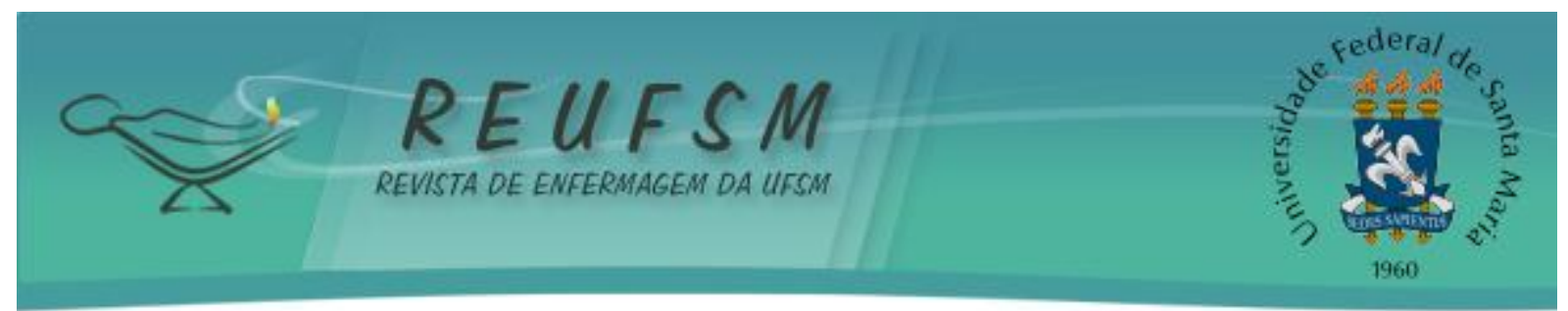

cateteres, com manuseio mínimo [...] não há como colocar no colo quando está intubado. (E6)

0 trabalho da equipe multiprofissional contribui para uma assistência qualificada ao recém-nascido internado na UTIN, com base nas melhores práticas e em evidências e recomendações preconizadas pelas instituições governamentais. Nuances, neste cenário, são relatadas nas falas a seguir:

falta estrutura e organização mesmo, da equipe médica e de enfermagem, de se reunir e chegar a um consenso, porque isso é importante.(E7)

Pela complexidade do cuidado no ambiente da UTIN, rotinas e normativas mais rígidas de cuidado são comumente presentes no cotidiano da enfermagem e a resistência para mudança pode interferir nos processos de cuidado humanizado. A fala a seguir faz menção as dificuldades encontradas frente as rotinas e falta de estrutura física para implementação do método.

Eu acho que as principais dificuldades são o manejo da enfermagem - aquela coisa de horários, de sinais vitais, tem horário para passar plantão, horário para o médico examinar, tem toda uma rotina da unidade que atrapalha muito o funcionamento do método. (E15)

Eu acho que aqui o que não tem é a estrutura - não tem uma cadeira adequada para mãe e para pegar o bebê, o espaço é pequeno. (E9)

\section{Benefícios do Método Canguru para o recém-nascido e sua família}

São inúmeros os benefícios do MC para o neonato internado na UTIN e sua família. Dentre eles, a promoção do vínculo entre o binômio e a família, o qual possibilita construir uma relação que foi interrompida pelas condições clínicas do recém-nascido:

acho que é todo aquele laço afetivo mesmo, para o bebê sentir que é a mãe dele, [...] é a ligação que eles precisam ter e que é roubada no neonatal, onde ficam dentro de uma incubadora ou de um berço cheio de tubos e fios. (E4)

A internação por vezes prolongada do recém-nascido na UTIN, pode gerar sentimentos e angustias da mãe frente ao cuidado e sobrevida de seu filho. A interrupção do vínculo entre o bebê e a família devido ao nascimento pré-termo, pode gerar insegurança na mãe. Percebe-se que, diante da complexidade do cuidado a partir de um ambiente tecnologico e intervencionista o MC pode proporcionar autonomia e confiança no retorno aos cuidados do recém-nascido e contribuir na construção de uma relação mais tranquila e restauradora entre a mãe e seu filho, como relatam as entrevistadas:

eu acho que a mãe fica mais segura, ela começa a conhecer o seu bebê, o choro - quando é dor e quando é fome. (E8) 


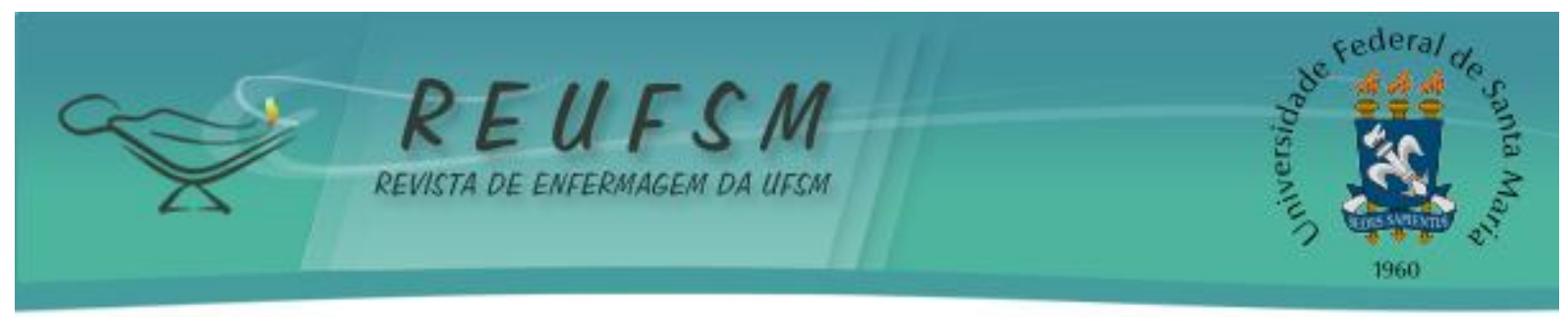

acho que as mães acabam se acalmando. O bebê também se acalma. Quando estão mais calmos, os bebês reagem melhor ao tratamento, fazem menos queda de saturação. (E6)

Além disso, o MC também pode contribuir na melhora das condições clínicas, no ganho de peso e no desenvolvimento do recém-nascido como informa a entrevistada a seguir:

o vínculo, a melhora do aleitamento materno, o maior ganho de peso para o recém-nascido, a melhora da função respiratória, o desenvolvimento neuropsicomotor do recém-nascido, e o sensorial também. (E11)

\section{Contribuições da equipe de enfermagem neonatal na implementação do Método Canguru}

Um dos fatores que contribuem para o método acontecer é a sensibilização da equipe de enfermagem, pois isso resulta em uma assistência mais humanizada e que, de alguma maneira, promove a aproximação da família com o recém-nascido. Assim, uma das entrevistadas relata o benefício da humanização por meio de suas iniciativas para a aproximação entre o binômio:

acho que é mais a humanização, você vê que a mãe nunca pegou no colo, e você quer dar aquele momento a ela. (E4)

Apesar da inexistencia de protocolos institucionais que garantam a prática do método na UTIN, iniciativas são tomadas pela equipe de enfermagem através de pequenos gestos, tais como o estímulo do toque e a oferta do colo. Essas condutas são realizadas para proporcionar um vínculo, mesmo que seja por alguns minutos:

na hora de trocar a incubadora ou de higienizar, às vezes a gente coloca o bebê no colinho da mãe por esses minutinhos. Todo o momento que a gente tem para promover esse vínculo, aproveitamos. (E4)

\section{DISCUSSÃO}

A análise das falas possibilitou entender que, para os entrevistados, a iniciativa da implementação do $M C$, mesmo que de forma parcial, significou garantir ao recém-nascido internado na UTIN a possibilidade de acesso a um cuidado humanizado e integral. Para eles, o cuidado humanizado, quando aliado à participação da família, promove o vínculo e auxilia no desenvolvimento do bebê.

O MC é baseado nos princípios da atenção humanizada, e tem como finalidades: a redução do tempo de afastamento entre a tríade familiar, o estímulo ao contato precoce pele a pele entre mãe e neonato, a possibilidade de um bom relacionamento entre a família e a equipe de saúde, o aumento dos índices de aleitamento materno e a redução das reinternações. ${ }^{3}$

Desenvolvido em três etapas, o MC inicia no pré-natal, com a preparação dos familiares a partir da descoberta de uma gestação de alto risco, e segue com o nascimento do neonato. A segunda etapa contempla o período em que o recém-nascido se encontra 


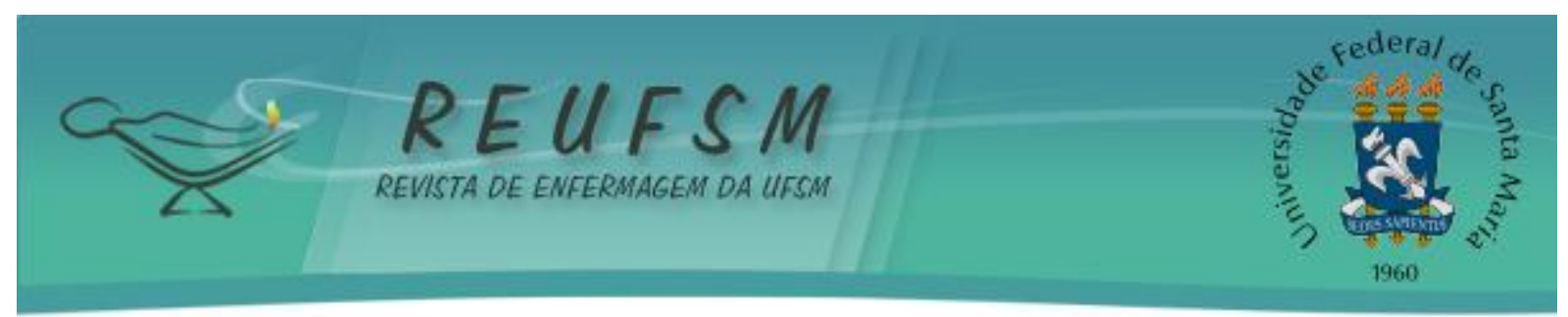

clinicamente estável e com peso mínimo de $1.250 \mathrm{~g}$, permanecendo com a mãe em tempo integral, desde que ela esteja em condições clínicas e psicológicas para recebê-lo. ${ }^{3}$

$\mathrm{Na}$ terceira e última etapa do método, os pais são os atores principais do cuidado de seu filho, e, por isso, precisam desenvolver competências para assumir seu papel. Aqueles que participam da implementação do $M C$ durante o período de internação neonatal mostram-se mais seguros e com maior autonomia para o cuidado no período de alta hospitalar. A enfermagem torna-se referência para os pais nesse processo de adaptação. ${ }^{10}$ Para isso, as tecnologias leves precisam se sobrepor às tecnologias duras. As tecnologias duras compreendem todo o cuidado que envolva o uso de insumos relativos ao parque tecnológico, tais como máquinas e aparelhos necessários para desenvolver as atividades assistenciais do cuidado. Em contrapartida, as tecnologias leves buscam potencializar as relações humanas, a partir do trabalho vivo em ato, em um processo relacional que busca desenvolver a confiança mútua, criando vínculos e compartilhamento de vivências do cotidiano em uma perspectiva da humanização do cuidado. ${ }^{11}$

Para que a proposta do MC seja garantida, torna-se imprescindível a elaboração e a validação de um Protocolo Operacional Padrão para a implementação do $M C$ de forma integral, contemplando todas as suas etapas.

Frente a isso, os participantes do estudo elucidaram dificuldades na prática do cuidado proposto pelo MC. A falta de capacitação dos colaboradores, assim como a resistência da equipe multiprofissional em executar as recomendações do método, mesmo que de forma parcial, oferecendo apenas o contato pele a pele do recém-nascido com sua mãe, constitui-se um dificultador do processo.

Corroborando essa afirmativa, autores ${ }^{12}$ mencionam que a força instituinte de alguns profissionais afronta a aceitação de novas práticas, a partir de posturas e conhecimentos já estabelecidos no trabalho, que os deixam mais confortáveis e embasados cientificamente. A falta de um protocolo que direcione a equipe multiprofissional quanto a oferta e orientação dos pais frente às possibilidades de participação no cuidado do recémnascido internado em uma UTIN pode deixar a família fragilizada e pouco habilitada para a realização do cuidado.

Evidenciou-se que a complexidade das atividades assistenciais ao recém-nascido, como aquelas com cateteres, em ventilação mecânica, com manuseio mínimo e com baixo peso, prematuros extremos e clinicamente instáveis, podem dificultar esta prática. Os critérios de elegibilidade para o recém-nascido participar da segunda etapa do MC e dizem respeito ao peso mínimo, que deve ser de $1.250 \mathrm{~g}$, e à estabilidade clínica. ${ }^{3}$ Indo de encontro a essa afirmativa, autores ${ }^{13}$ afirmam que o método gera benefícios mesmo em neonatos com idade gestacional inferior a 30 semanas e peso médio de $1.044 \mathrm{~g}$, sob ventilação mecânica. Esses autores salientam, ainda, que a prática pode ser segura, apesar da importância de se verificar a temperatura corporal do neonato constantemente.

Os benefícios da atenção humanizada em um ambiente hospitalar diferem positivamente daqueles resultantes do modelo biológico e tecnocêntrico de cuidado, pois se busca a atenção ao recém-nascido na sua integralidade. Na UTIN, não é diferente. Os entrevistados deste estudo percebem os benefícios de uma atenção humanizada com ferramentas tecnológicas leves, como a iniciativa do $M C$. Mesmo que a prática não esteja sendo implementada integralmente, os benefícios proporcionados ao recém-nascido e à sua família no cotidiano da unidade são percebidos.

Nesse sentido, o MC objetiva melhores condições de relacionamento entre a família e o recém-nascido, estabelecendo credibilidade e confiança, e reduzindo angústias. 0 suporte familiar é fundamental para a recuperação do neonato, pois é necessário que os pais se sintam confiantes e disponíveis para dedicação integral ao bebê, vivenciando e contribuindo para sua evolução. ${ }^{14}$ A hospitalização em UTIN expõe o neonato a um 


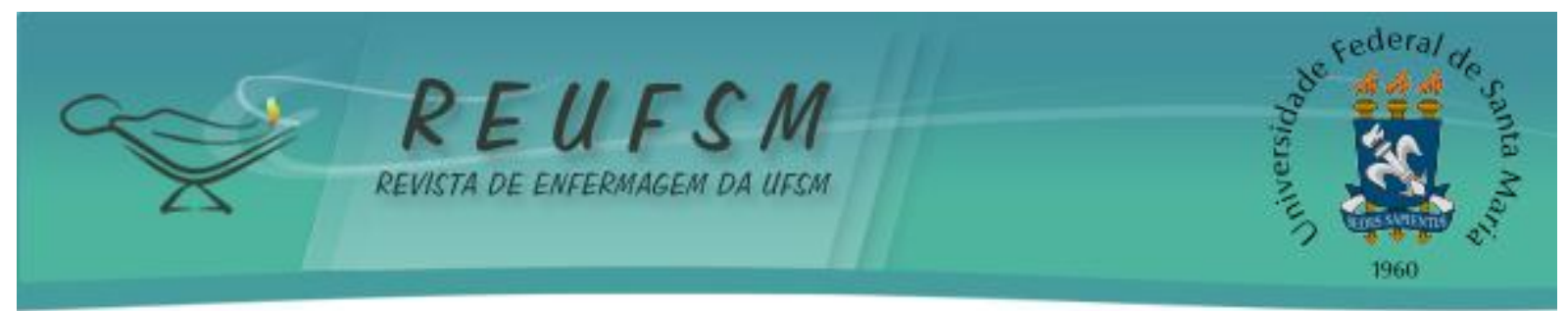

ambiente limitado, onde é submetido a estímulos desagradáveis, tais como luz intensa, ruídos constantes, manipulações e procedimentos invasivos, o que potencializa o estresse e a dor. Com o intuito de amenizar essa situação, há necessidade de incluir a família no cenário do cuidado semi-intensivo ou intensivo neonatal. ${ }^{15}$

Esse método propicia confiança, satisfação, tranquilidade e segurança ao binômio, melhora o vínculo entre mãe e bebê, proporciona estabilidade térmica, estimula o aleitamento materno, melhora o desenvolvimento afetivo e neuropsicomotor, diminui infecções, dores e estresse. Sobretudo, o aleitamento materno, além de prevenir e de reduzir a morbimortalidade infantil, representa uma estratégia natural de vínculo, apego, amparo e nutrição para o neonato, pois promove saúde integral ao binômio mãe-bebê, envolve interação intensa entre mãe e filho, com auxílio no desenvolvimento cognitivo e emocional, além de benefícios para a saúde - psíquica e física - da mãe. ${ }^{3}$

\section{CONSIDERAÇÕES FINAIS:}

O presente estudo permitiu constatar que a política do $M C$ não está sendo implementada de forma integral, conforme preconizado pelo Ministério da Saúde. Iniciativas são tomadas por alguns profissionais no que ser refere à prática do contato pele a pele entre mãe e bebê, quando internado em UTIN.

De qualquer maneira, benefícios relacionados a prática do método são identificados pela equipe de enfermagem e reforçam a necessidade de mudança de paradigmas na assistência neonatal. A complexidade do cuidado na UTIN pode gerar dificuldades operacionais na implementação do $M C$ a partir do enfoque em rotinas e normas pouco flexíveis para introdução da família no processo de humanização da assistência.

A falta de protocolo que normatize e sistematize o cuidado para com recémnascidos prematuros ou de baixo peso pode constitui-se em um dos principais limitadores na atenção do cuidado humanizado neste cenário. A educação continuada torna-se indispensável para qualificar e padronizar a prática.

Faz-se necessário qualificar a atenção ao cuidado integral e humanizado ao recémnascido e sua família na UTIN. Novos estudos com essa temática podem ser realizados em serviços de saúde privados, buscando vislumbrar possibilidades de melhoria e implementação de práticas baseadas em evidências recomendadas pelas instituições governamentais.

\section{REFERÊNCIAS}

1. Matijasevich A, Silveira MF, Matos ANG, Rabello Neto DL, Fernandes RM, Maranhão AG, et al. Estimativas corrigidas da prevalência e nascimentos pré-termo no Brasil, 2000-2011. Epidemiol Serv Saúde. 2013 [acesso em 2016 dez 29];22(4):557-64. Disponível em: https://www.unicef.org/brazil/pt/br_prematuridade_anexo3.pdf.

2. Silva JR, Thomé CR, Abreu RM. Método mãe canguru nos hospitais/maternidades públicos de Salvador e atuação dos profissionais da saúde na segunda etapa do método. Rev CEFAC [Internet]. 2011 [acesso em 2016 dez 28];13(3):522-33. Disponível em: http://www.scielo.br/pdf/rcefac/v13n3/15.pdf.

3. Brasil. Ministério da Saúde. Atenção humanizada ao recém-nascido de baixo peso método canguru. Brasília: Ministério da Saúde; 2011.

4. Frigo J, Zocche DAA, Palavro GL, Turatti LA, Neves ET, Schaefer TM. Percepções de pais de recém-nascidos prematuros em unidade de terapia intensiva neonatal. Rev Enferm UFSM [Internet]. 2015 [acesso em 2016 dez 28];5(1):58-68. Disponível em: https: //periodicos.ufsm.br/reufsm/article/view/12900. 


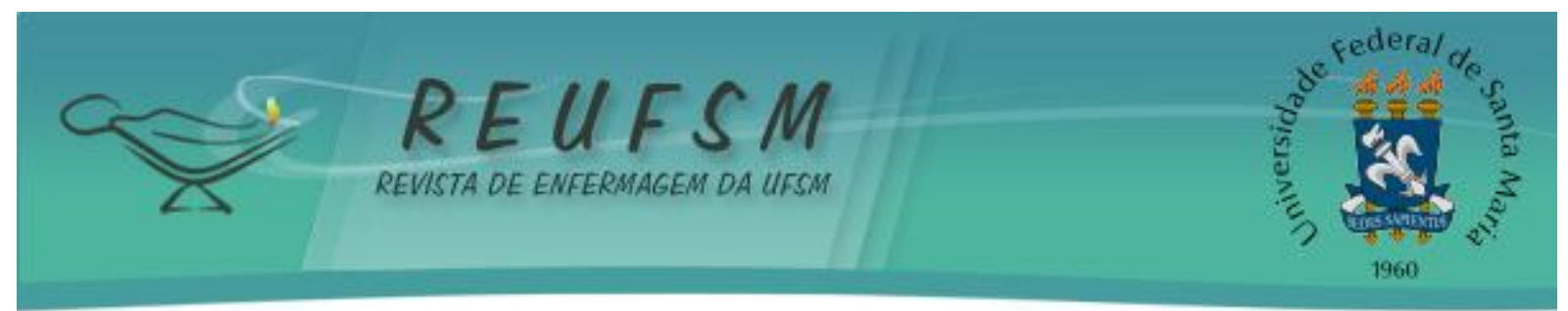

5. Strapasson MR, Costa CS. The kangaroo mother method in the care to the low weight newborn infant: integrative literature review. J Nurs UFPE Online [Internet]. 2012 [acesso em 2015 abr 28];6(10):2535-41.Disponível em: http://www.revista.ufpe.br/revistaenfermagem/index.php/revista/article/view/2538.

6. Blanca Gutiérrez JJ, Ábalos Pérez MR, Montes Aguilera MV, González Moreno S. The role of fathers in the postpartum period: experiences with skin to skin method. Acta Paul Enferm. 2012 [acesso em 2016 dez 28];25(6):914-20. Disponível em: http://www.scielo.br/pdf/ape/v25n6/v25n6a14.pdf.

7. Minayo MC. Ciência, técnica e arte: desafio da pesquisa social. In: Minayo MCS, Deslandes SF, Gomes R, editores. Pesquisa social: teoria, método e criatividade. Petrópolis: Vozes; 2012. p. 9-29.

8. Gaskell G. Entrevistas individuais e de grupos. In: Bauer MW, Gaskell G, organizadores. Pesquisa qualitativa com texto, imagem e som: um manual prático. Petrópolis (RJ): Vozes; 2013. p. 64-89.

9. Brasil. Conselho Nacional de Saúde. Resolução $n^{\circ}$ 466, de 12 de dezembro de 2012. Aprova normas regulamentadoras de pesquisas envolvendo seres humanos. Brasília: Diário Oficial da União, Brasília; 2013 jun 13. Seção 1, p. 59-62.

10. Heck GMM, Huiana Cristine Lucca HC, Costa R, Junges CF, Santos SV, Borck M. Compreensão do sentimento materno na vivencia no Metodo Canguru. Rev Enferm UFSM $2016 \mathrm{jan} / \mathrm{mar}$ [acesso em 2016 dez 28];6(1):71-83. Disponível em: https: / / periodicos.ufsm.br/reufsm/article/view/18083.

11. Merhy EE. Em busca de ferramentas analisadoras das tecnologias em saúde: a informação e o dia a dia de um serviço, interrogando e gerindo trabalho em saúde. In: Merhy $\mathrm{EE}$, Onocko $\mathrm{R}$, editores. Agir em saúde: um desafio para o público. São Paulo: Hucitec; 1997. p. 113-50.

12. Gontijo TL, Xavier CC, Freitas MIF. Avaliação da implantação do Método Canguru por gestores, profissionais e mães de recém-nascidos. Cad Saúde Pública. 2012;28(5):935-44.

13. Azevedo VMGO, David RB, Xavier CC. Cuidado mãe canguru em recém-nascidos prétermo sob suporte ventilatório: avaliação dos estados comportamentais. Rev Bras Saúde Matern Infant. 2011;11(2):133-8.

14. Maia JA, Oliveira MP, Furtado SS, Silva LM, Pereira MLB. Método Canguru: a importância da família na recuperação do recém-nascido de baixo peso. Enfermagem em Foco 2011 [acesso em 2016 dez 29];2(4):231-4. Disponível em: http://revista.portalcofen.gov.br/index.php/enfermagem/article/view/190.

15. Santos LM, Morais RA, Miranda JOF, Santana RCB, Oliveira VM, Nery FS. Percepção materna sobre o contato pele a pele com prematuro através da posição canguru. Rev Pesqui Cuid Fundam [Internet]. 2013 [acesso em 2016 dez 29];5(1):3504-14. Disponível em: http://pesquisa.bvsalud.org/portal/resource/pt/lil-686248.

Data de recebimento: $20 / 02 / 2016$

Data de aceite: 23/05/2017

Contato com autor responsável: Gabriela Vieira Mantelli

E-mail: gabrielamantelli@hotmail.com 